\title{
Pulmonary function assessment in patients with type 2 diabetes mellitus
}

\author{
Maqsood S. ${ }^{1}$, Mehani R. ${ }^{2 *}$ \\ DOI: https://doi.org/10.17511/ijmrr.2021.i01.03 \\ 1 Sheema Maqsood, Assistant Professor, Department of Pulmonary Medicine, RKDF Medical college \& hospital, Bhopal, Madhya Pradesh, \\ India. \\ 2* Rekha Mehani, Associate professor, Department of pharmacology, RKDF Medical college \& hospital, Bhopal, Madhya Pradesh, India.
}

Introduction: Diabetes mellitus is a leading public health problem all over the world. Diabetes mellitus is a risk factor that precipitating microvascular as well as macro-vascular pathologies. Several respiratory alterations have been reported in associations with Diabetes Mellitus. Therefore, the present study was designed to determine the effect of the disease on respiratory function in patients with diabetes. Method \& material: For this study 54 Diabetes Mellitus patients were selected using simple random sampling from the diabetic clinic. 54 Non-diabetic, age \& sex-matched subjects were also taken from teaching and non-teaching employees of the hospital for comparison. Result: In our study there was a statistically significant decrease in the level of FVC in DM patients compared to healthy male subjects. There was a statistically significant increase in the level of ratio of FEV1/FVC. A more sensitive index of early disease is FEV1/ FVC ratio. Conclusion: Spirometric values were consistently lower in subjects with diabetes mellitus than in non-diabetics. Subjects with poorer diabetic control have a worse spirometric function. We conclude that strict glycaemic control \& regular breathing exercises to strengthen the respiratory muscles may improve the pulmonary function test in patients.

Keywords: Diabetes mellitus, Spirometry, Pulmonary function test, Forced Vital Capacity

Corresponding Author

Rekha Mehani, Associate professor, Department of pharmacology, RKDF Medical college \& hospital, Bhopal, Madhya Pradesh, India.

Email: drrekhasanjay@gmail.com

\section{How to Cite this Article}

Maqsood S, Mehani R. Pulmonary function assessment in patients with type 2 diabetes mellitus. Int J Med Res Rev. 2021;9(1):21-28.

Available From

https://ijmrr.medresearch.in/index.php/ijmrr/article/ view/1246
To Browse

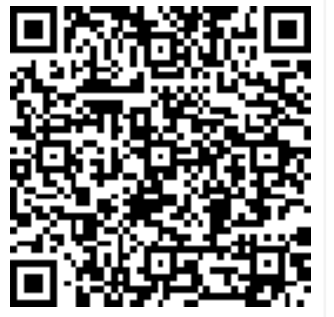

Manuscript Received 2021-01-19

Conflict of Interest No

Review Round 1
2021-02-10
Funding
Nil

Review Round 1

$\mathrm{Nil}$

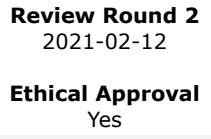

Review Round 3

Accepted 2021-02-15

Plagiarism X-checker $6 \%$
Note

(c) 2021 by Sheema Maqsood, Rekha Mehani and Published by Siddharth Health Research and Social Welfare Society. This is an Open Access article licensed under a Creative Commons Attribution 4.0 International License https://creativecommons.org/licenses/by/4.0/ unported [CC BY 4.0]. 


\section{Introduction}

Diabetes mellitus is a metabolic disorder of multiple etiologies with disturbance of carbohydrates, fat and protein metabolism due to which there are defects in insulin secretion and or insulin action, characterized by chronic hyperglycemia [1]. Diabetes mellitus is a leading public health care problem in developing countries and the developing world, along with increasing incidence and long term complications.

Today an epidemic of diabetes mellitus (DM), globally and nationally is been witnessed. DM and its complications have become the most important challenging health problem. There are 150 million diabetics worldwide where In India more than 3 crores have been affected.

According to etiopathogenic categories, it is classified as Type- 1 and Type- 2 diabetes mellitus. In Type-1 insulin secretion is deficient whereas in Type-2 there is a combination of resistance to insulin action and inadequate compensatory insulin secretory response. Diabetes is multisystem disorders that affect several organs of the body [2]. There is an alarming increase in the incidence and prevalence of Diabetes Mellitus mainly in Asian Indians [3].

Diabetes mellitus is a risk factor with precipitating microvascular pathologies involving autonomic neuropathy, nephropathy, retinopathy, peripheral neuropathy, and macrovascular pathologies leading to coronary artery disease, Cerebrovascular accidents and peripheral vascular disease. The microvascular complications appear early, within 5 to 10 years and macrovascular complications appear within 15 to 20 years from the onset of diabetes if the diabetes mellitus detected early and adequate treatment is given, it can be possible to significantly delay the occurrence of complications and thereafter the progression $[4,5]$.

Several respiratory alterations have been seen in associations with Diabetes Mellitus, including respiratory muscle dysfunction, and chest wall abnormalities. As it is well known that Diabetes Mellitus may damage the autonomic nervous system of virtually all organs. Diabetes mellitus is known for chronic complications particularly the triad of neuropathy, retinopathy and nephropathy which have a close relation with the metabolic abnormalities characteristic of diabetes.
Neuropathy is one of the common complications of diabetes and specifically autonomic neuropathy which can affect several systems with clinical manifestations of dysautonomia being more common in the cardiovascular, genitourinary, gastrointestinal and thermoregulatory systems [5]. Diabetic autonomic neuropathy (DAN) frequently coexists with other peripheral neuropathies and other diabetic complications. Despite its relationship to an increased risk of cardiovascular mortality and its association with multiple symptoms and impairments, the significance of the DNA has not been fully satisfied and appreciated [6].

The pathogenesis of diabetic complications involves both a microangiopathic process and non-enzymatic glycosylation of tissue proteins. This process leads to impaired collagen and elastin cross linkage with a reduction in strength and elasticity of connective tissue. The presence of abundant connective tissue and an extensive microvascular circulation in the lung increases the possibility that the lung may be a target organ in diabetic patients $[7,8]$.

The pulmonary complications of diabetes mellitus have not been characterized. Some authors have reported normal pulmonary function8, whereas in other cases it has been found abnormal lung function. $[9,10]$. Moreover, physicians should be aware of the pulmonary complications in diabetes when they prescribe novel insulin delivery systems, for example inhaled insulin. Therefore, the present study was designed to determine the effect of the disease on respiratory function in patients with diabetes who resides in the rural region of Bhanpur, Bhopal.

There are histopathological changes seen in the lungs of diabetics such as thickened alveolar epithelial cells and pulmonary capillary basal lamina results in reduced pulmonary elastic recoiling of lung tissue. There is impaired diffusion of gases because of reduced pulmonary capillary blood volume and thickening of the basement membrane. Non-enzymatic glycosylation induces alteration of lung connective tissue is most thought to be the mechanism underlying the mechanical pulmonary dysfunction in diabetic subjects. This states that the lung is one of the 'target organ' in diabetes mellitus [11].

Diabetes mellitus is associated with an ongoing malfunction of numerous organs and its complications are likely a consequence of macrovascular and microvascular damage. 
Parasympathetic regulation of airway calibre may be destroyed in diabetes mellitus characterizing a bronchomotor dysautonomia [12].

The alveolar-capillary network because of its large size is protected against overt respiratory complication at a given level of systemic microvascular destruction. Therefore lung function could provide a useful measure of progression of systemic microangiopathy and noninvasively quantifies physiological reserve in large microvascular bed [13].

An improved understanding of the natural history of diabetic lung function is needed when pulmonary delivery of insulin is actively being pursued as a treatment option [14].

\section{Methodology}

The present study was conducted in the Department of Pulmonary Medicine, People's College of Medical Sciences and RC, Bhopal.

The study was undertaken to observe the effects of diabetes mellitus on the pulmonary functions of subjects of age group 15-60 years. The pulmonary function of patients was compared with the healthy subjects with no history of smoking. Age, Gender, BMI, blood sugar levels are considered to study the effect of diabetes mellitus on pulmonary function tests.

Study group: 54 Diabetes Mellitus patients (males $\mathrm{n}=25$, Females $\mathrm{n}=15$ ) taken from the diabetic clinic of People's College of Medical Sciences \& Research Centre, Bhopal.

Control group: 54 Non-diabetic age \& sexmatched subjects taken from teaching and nonteaching employees of People's College of Medical Sciences \& Research Centre, Bhopal.

Age of the subjects: In both the group's subjects in the age group of 15 - 60 years were included in the study. Both males and females are included understudy group.

Sampling Technique: 54 subjects were selected using simple random sampling.

Patients included were male and female suffering from DM, Non-obese diabetics, Aged between 15$60 y r s, B M I<25 \mathrm{~kg} / \mathrm{m} 2$, Physically and mentally fit, Cooperative and capable of understanding the procedure.
The patient suffering from asthma, COPD, any chronic diseases, Smokers and Tobacco chewers, Patients on long term steroids, Obese were excluded.

Parameters recorded in the subjects were 01. Record of Physical Anthropometry of subjects

- Height in centimetres b. Weight in kilograms c. Body Mass Index in $\mathrm{kg} / \mathrm{m} 2$

02. Record physiological parameters.

- Pulse rate. It is expressed as beats per minute. The right radial pulse is examined by compressing the radial artery in the semi pronated forearm and slightly flexed wrist of the subject.

- Blood pressure. It is measured by a mercury sphygmomanometer (Diamond make) in $\mathrm{mm}$ of $\mathrm{Hg}$ by palpatory and auscultatory methods.

- Respiratory rate. It is recorded by inspection \& palpation of the chest and abdomen and will be expressed as cycles per minute

\section{Pulmonary function parameters.}

The subject was informed about the procedure, and consent has been taken before recording. For each test, three readings are taken. The highest reading was taken for the calculation. All tests are recorded in a sitting posture at room temperature, in the morning hours.

The following parameters are recorded:

01. FVC (Forced Vital Capacity):

02. FEV1 (Forced Expiratory Volume at the end of First Second):

03. FEV1\% (Percentage of Forced Expiratory Volume at the end of one second):

04. PEFR (Peak Expiratory Flow Rate):

05. Glycemic status of a diabetic patient

\section{Statistical analysis}

The data obtained was subjected to statistical analysis with the consult of a statistician. The data so obtained was compiled systematically. A master table was prepared and the total data was subdivided and distributed meaningfully and presented as individual tables along with graphs. 
Statistical procedures were carried out in 2 steps:

02. Data compilation and presentation

03. Statistical analysis

Statistical analysis was done using Statistical Package of Social Science (SPSS Version 19; Chicago Inc., USA). Data comparison was done by applying specific statistical tests to find out the statistical significance of the comparisons. Quantitative variables were compared using mean values and qualitative variables using proportions. Chi-Square test, Student Unpaired t-test, Analysis of Variance (ANOVA) \& Pearson Correlation\& Turkeys Post Hoc test were applied to compare the data. The significance level was fixed at $P \leq 0.05$.

\section{Results}

A total number of 108 cases were suitable for analysis. There were 54 diabetics in STUDY GROUP and 54 non-diabetics in the control group.

Table 1: Distribution of study subjects among Case \& Control according to Age

\begin{tabular}{|l|l|l|l|}
\hline AGE GROUPS (YEAR) & CASE N(\%) & CONTROL N(\%) & TOTAL N(\%) \\
\hline $15-30$ Year & $8(14.8 \%)$ & $1(1.9 \%)$ & $9(8.3 \%)$ \\
\hline $31-45$ year & $26(48.1 \%)$ & $28(51.9 \%)$ & $54(50 \%)$ \\
\hline $46-60$ year & $20(37 \%)$ & $25(46.3 \%)$ & $45(41.7 \%)$ \\
\hline TOTAL & 54 & 54 & \\
\hline Chi Square value & 6.074 & \\
\hline P value & 0.048 (Significant) \\
\hline
\end{tabular}

Table 1 reveals distribution of cases and control according to age. Out of 108 study subject there were 54 cases and 54 control. Maximum number of subjects were in 31-45 year of age group while in 15-30years age group were the least only 9 . There was statistically significant difference between cases and control according to age.

Table 2: Distribution of study subjects among Case \& Control according to gender

\begin{tabular}{|l|l|l|l|}
\hline \multicolumn{1}{|c|}{ GENDER } & CASE N (\%) & CONTROL N (\%) & TOTAL N (\%) \\
\hline MALE & $35(64.8 \%)$ & $35(64.8 \%)$ & $70(64.8 \%)$ \\
\hline FEMALE & $19(35.2 \%)$ & $19(35.2 \%)$ & $38(35.2 \%)$ \\
\hline Chi Square Value & 1.00 & \\
\hline P Value & 0.580 (Not significant) \\
\hline
\end{tabular}

Table 2 reveals distribution of cases and control according to gender. Out of 108 study subjects there were 70 male and 38 were females. Male were more in number as compare to female. In both cases and control there was no statistically significant difference according to gender.
TABLE-3: Mean Spirometric Values between Case \& Control

\begin{tabular}{|c|c|c|c|c|c|c|}
\hline \multirow{2}{*}{$\begin{array}{c}\text { PULMONARY FUNCTION } \\
\text { TESTS }\end{array}$} & \multicolumn{2}{|c|}{ CASE } & \multicolumn{2}{|c|}{ CONTROL } & \multirow{2}{*}{$\begin{array}{l}\text { t-Test } \\
\text { Value }\end{array}$} & \multirow[t]{2}{*}{ P valuc } \\
\hline & MEAN & SD & MEAN & SD & & \\
\hline FVC & 74.65 & 18.14 & 97.47 & 16.55 & 6.825 & $\begin{array}{l}0.001 \\
(\mathrm{HS})\end{array}$ \\
\hline FEV1 & 88.08 & 30.58 & 95.65 & 16.16 & 1.608 & $\begin{array}{l}0.111 \\
(\mathrm{NS})\end{array}$ \\
\hline PEF & 79.31 & 24.28 & 87.75 & 13.64 & 2.226 & $0.02(\mathrm{~S})$ \\
\hline FEV1/FVC & 76.50 & 16.45 & 89.70 & 16.23 & 4.193 & $\begin{array}{l}0.001 \\
(\mathrm{HS})\end{array}$ \\
\hline
\end{tabular}

Table 3 reveals mean spirometric values between case and control. Mean FVC were lesser in cases than control ie $74.65+\ldots 18.14$ vs 97.47 respectively. There was a statistically highly significant difference between cases and control in aspect to FVC ( $P=$ 0.001).

FEV1, PEF \& FEV1/FVC were also lesser in cases as compared to control but in respect to FEV1 there was no statistically significant difference between case and control $(P=0.111)$ while PEF \& FEV1/FVC was statistically significant.

TABLE-4: Mean Spirometric Values according to gender

\begin{tabular}{|c|c|c|c|c|c|c|}
\hline \multirow{2}{*}{$\begin{array}{c}\text { PULMONARY FUNCTION } \\
\text { TESTS }\end{array}$} & \multicolumn{2}{|c|}{ MALE } & \multicolumn{2}{|c|}{ FEMALE } & \multirow{2}{*}{$\begin{array}{l}\text { t-Test } \\
\text { Value }\end{array}$} & \multirow[t]{2}{*}{ P-value } \\
\hline & MEAN & SD & MEAN & SD & & \\
\hline FVC & 86.77 & 21.32 & 84.75 & 19.82 & 0.483 & $\begin{array}{l}0.630 \\
(\mathrm{NS})\end{array}$ \\
\hline FEV1 & 90.76 & 19.93 & 93.89 & 31.74 & 0.629 & $\begin{array}{l}0.531 \\
(\mathrm{NS})\end{array}$ \\
\hline PEF & 82.85 & 20.55 & 84.79 & 19.30 & 0.479 & $\begin{array}{l}0.633 \\
(\mathrm{NS})\end{array}$ \\
\hline FEV/FVC & 83.26 & 18.85 & 82.81 & 15.15 & 0.126 & $\begin{array}{l}0.900 \\
(\mathrm{NS})\end{array}$ \\
\hline
\end{tabular}

Table-4 reveals mean spirometric values between case and control according to gender. Mean FVC and FEV1/FVC were higher in males than females i.e. $86.77+221.32$ vs $83.26+\_18.85$ respectively. There was statistically no significant difference between males and females.

While FEV1 \& PEF were higher in females as compared to males but there was no statistically significant difference between male and female $(P=$ $0.531 \& P=0.633$ ) respectively.

TABLE-5: Mean Spirometric Values according to BMI. 
Maqsood S. et al: Pulmonary function assessment in patients

\begin{tabular}{|c|c|c|c|c|c|c|c|c|}
\hline BMI & \multicolumn{2}{|c|}{$1(<18.5)$} & \multicolumn{2}{|c|}{$2(18.5-22.9)$} & \multicolumn{2}{|c|}{$3(23.0-25.0)$} & \multirow[t]{3}{*}{ F Value } & \multirow[t]{3}{*}{ P Value } \\
\hline Number of study subjects & \multicolumn{2}{|l|}{11} & \multicolumn{2}{|l|}{95} & \multicolumn{2}{|l|}{02} & & \\
\hline Pulmonary Function Test & MEAN & SD & MEAN & SD & MEAN & SD & & \\
\hline FVC & 73.72 & 17.72 & 87.28 & 20.68 & 96.16 & 25.22 & 2.410 & 0.095 (NS) \\
\hline FEV1 & 76.18 & 11.95 & 93.50 & 24.78 & 100.40 & 51.75 & 2.635 & $0.076(\mathrm{NS})$ \\
\hline PEF & 73.49 & 18.43 & 84.61 & 20.20 & 87.71 & 4.64 & 1.575 & 0.212 (NS) \\
\hline FEV1/FVC & 81.74 & 19.86 & 83.26 & 17.40 & 83.00 & 24.04 & 0.036 & $0.964(\mathrm{NS})$ \\
\hline
\end{tabular}

TABLE-5(A): POST HOC Analysis for intergroup comparison

\begin{tabular}{|c|c|c|c|}
\hline & & MEAN DIFFERENCE & P-Value \\
\hline \multirow[t]{3}{*}{ FVC } & 1 VS 2 & 13.55 & 0.099 (NS) \\
\hline & 1 VS 3 & 22.43 & 0.331 (NS) \\
\hline & 2 VS 3 & 8.87 & 0.817 (NS) \\
\hline \multirow[t]{3}{*}{ FEV1 } & 1 VS 2 & 17.31 & 0.069 (NS) \\
\hline & 1 VS 3 & 24.21 & 0.399 (NS) \\
\hline & 2 VS 3 & 6.90 & 0.917 (NS) \\
\hline \multirow[t]{3}{*}{ PEF } & 1 VS 2 & 11.11 & 0.192 (NS) \\
\hline & 1 VS 3 & 14.22 & 0.624 (NS) \\
\hline & 2 VS 3 & 3.10 & 0.974 (NS) \\
\hline
\end{tabular}

\begin{tabular}{|l|l|l|l|}
\hline FEV1/FVC & 1 VS 2 & 1.52 & $0.961(\mathrm{NS})$ \\
\cline { 2 - 4 } & 1 VS 3 & 1.25 & $0.995(\mathrm{NS})$ \\
\cline { 2 - 4 } & 2 VS 3 & 0.26 & $1.00(\mathrm{NS})$ \\
\hline
\end{tabular}

Table 5 \& 5(a) with figure 5 reveals mean spirometric values according to BMI. All the values were higher in BMI category 3 in comparison to category 1 and 2 subjects. FVC \& FEV1 were $73.72+17.72$ \& $76.18+11.91$ in BMI category 1subjects respectively while there were $96.16+25.22 \& 100.40+51.75$ in BMI category 3subjects. But there was no statistically significant difference in spirometric values concerning BMI.

TABLE-6: Mean Spirometric Values according to Age

\begin{tabular}{|c|c|c|c|c|c|c|c|c|}
\hline Age Groups & \multicolumn{2}{|c|}{$15-30$ year } & \multicolumn{2}{|c|}{$31-45$ year } & \multicolumn{2}{|c|}{ 46-60 year } & \multirow[t]{3}{*}{ F Value } & \multirow[t]{3}{*}{ P-Value } \\
\hline Number & \multicolumn{2}{|l|}{9} & \multicolumn{2}{|l|}{54} & \multicolumn{2}{|l|}{45} & & \\
\hline Pulmonary Function Test & MEAN & SD & MEAN & SD & MEAN & SD & & \\
\hline FVC & 73.00 & 20.30 & 85.71 & 21.70 & 89.09 & 18.94 & 2.331 & 0.102 (NS) \\
\hline FEV1 & 84.11 & 22.38 & 91.32 & 20.88 & 94.06 & 29.01 & 0.634 & $0.532(\mathrm{NS})$ \\
\hline PEF & 66.37 & 31.95 & 84.78 & 16.52 & 85.47 & 19.94 & 3.798 & $0.026(\mathrm{~S})$ \\
\hline FEV1/FVC & 76.22 & 16.83 & 83.04 & 18.34 & 84.55 & 16.79 & 0.841 & $0.434(\mathrm{NS})$ \\
\hline
\end{tabular}

TABLE 6(A): POST HOC Analysis for intergroup comparison

\begin{tabular}{|c|c|c|c|}
\hline & & MEAN DIFFERENCE & P-Value \\
\hline \multirow[t]{3}{*}{ FVC } & 1 VS 2 & 12.71 & 0.201 (NS) \\
\hline & 1 VS 3 & 16.09 & 0.084 (NS) \\
\hline & 2 VS 3 & 3.38 & 0.693 (NS) \\
\hline \multirow[t]{3}{*}{ FEV1 } & 1 VS 2 & 7.21 & 0.697 (NS) \\
\hline & 1 VS 3 & 9.95 & 0.514 (NS) \\
\hline & 2 VS 3 & 2.74 & 0.847 (NS) \\
\hline \multirow[t]{3}{*}{ PEF } & 1 VS 2 & 18.40 & $0.027(S)$ \\
\hline & 1 VS 3 & 19.10 & $0.023(\mathrm{~S})$ \\
\hline & 2 vs 3 & 0.69 & 0.983 (NS) \\
\hline \multirow[t]{3}{*}{ FEV1/FVC } & 1 VS 2 & 6.82 & 0.531 (NS) \\
\hline & 1 VS 3 & 8.32 & 0.400 (NS) \\
\hline & 2 VS 3 & 1.50 & $0.905(\mathrm{NS})$ \\
\hline
\end{tabular}

Table $6 \& 6(a)$ with figure 6 reveals mean spirometric values according to age. All values are increasing with the increase in age.
Mean FVC \& FEV1 values were 73.0+_20.30 \& $84.11+22.38$ respectively while these values were higher in the age group of 46-60 years of age i.e. 89.09+_18.94 \& 94.06+_29.01 respectively but there was a statistically significant difference in PEF $(P=0.026)$ but there was no statistically significant difference in FVC, FEV1 \& FEV1/FVC in respect to age.

TABLE-7: Pearson Correlation between FBS \& Pulmonary Function Tests

\begin{tabular}{|l|l|l|l|l|l|l|}
\hline \multicolumn{7}{|c|}{ Correlations } \\
\hline \multicolumn{2}{|c|}{} & FBS & FVC $\%$ & FEV1 \% & PEF \% & FEV1/FVC \\
\hline \multirow{3}{*}{ FBS } & Pearson Correlation & 1 & $-.492 * *$ & -.176 & $-.235^{*}$ & $-.215^{*}$ \\
\cline { 2 - 7 } & P Value & & .001 & .068 & .014 & .026 \\
\cline { 2 - 7 } & Number & 108 & 108 & 108 & 108 & 108 \\
\hline
\end{tabular}

Table 7 reveals Pearson correlation between FBS and various spirometric values. FBS had significant negative correlation with FVC $(r=-0.492)$; PEF $(r=$ 
-0.235) and FEV1/FVC $(r=-0.215)$ while FBS had no significant correlation with FEV1 $(r=-0.176)$.

\section{Discussion}

This study was done for evaluation of changes in the ventilatory function of type 2 diabetes mellitus patients, and to compare it with those of nondiabetic healthy subjects. It also analyzes the effect of Diabetes on pulmonary functions. The subjects with the study group were screened with proper history taking \& thorough clinical examination. The anthropometric parameters like age(years), Height (centimetres), Weight (kilograms), Body mass index $(\mathrm{kg} / \mathrm{m} 2)$, was recorded in both groups. Anthropometric parameters do not vary significantly among the subjects of the two groups. Physiological parameters like Pulse rate (beats/min), Respiratory rate (cycles/min), Systolic and Diastolic blood pressure $(\mathrm{mmHg})$ were recorded in both groups.

Pulmonary function tests were performed on 108 subjects who were divided into 2 groups, 54 DM patients and 54 healthy adult subjects. All the subjects were in between the age group of 15-60 years. DM patients were again grouped into many groups based on the BMI fasting blood sugar level and postprandial blood sugar level. The differences in the mean value of each parameter between DM patients and healthy controls, the difference between each parameter in DM patients based on Age, Gender, BMI, FBS and PPBS level were analysed and discussed [12].

\section{FVC:}

In our study there was a statistically significant decrease in the level of FVC in DM patients compared to healthy male subjects. It is also shown that the level of FVC decreases more with an increase in the level of FBS and PPBS. In diabetes mellitus thickening of the alveolar epithelium and pulmonary capillary basal lamina leads to pulmonary microangiopathy and reduced pulmonary elastic recoiling of the lung caused by nonenzymatic glycosylation of the connective tissue which reduces the FVC in diabetes mellitus [13].

\section{FEV1:}

In our study there was no statistically significant difference in the level of FEV1 in DM patients compared to healthy male adults. There was a decrease in $14.2 \%(0.88 \mathrm{~L})$ of predicted FEV1 value in DM Patients.
It was observed that FEV1 decreases more with the increase in the level of FBS and PPBS [14]. In diabetes mellitus thickening of the alveolar epithelium and pulmonary capillary basal lamina occurs leading to pulmonary microangiopathy and reduced pulmonary elastic recoil caused by nonenzymatic glycosylation of the connective tissue which also reduces the FEV1 in diabetes mellitus.

\section{The ratio of FEV1/ FVC :}

In our study there was a statistically significant increase in the level of ratio of FEV1/FVC. DM patients showed an increase of $10.5 \%$ when compared to healthy adult male subjects. It shows that the ratio of FEV1/FVC was significantly increased with an increase in the level of FBS and PPBS, which was statistically significant $(p<0.05)$. The present study correlates with Robert WE et al who studied the relationship between diabetes mellitus and pulmonary function and showed a $1.5 \%$ increase in the FEV1/FVC ratio with a P-value $<0.05 \%$ which is statistically significant, suggesting a restrictive pattern of pulmonary dysfunction. FEV1/ FVC ratio is a more sensitive index of early disease. As mentioned above diabetes leads to changes in FVC and FEV1, therefore this ratio is affected.

\section{PEFR :}

Our study shows a statistically significant decrease in the level of PEFR $(14.1 \%$ of percentage predicted). It has also shown that, the PEFR decreases more with an increase in the level of FBS and PPBS. The reduced flow rate is due to a reduction in the force-generating capacity of expiratory muscles, higher airway resistance, reduced recoiling nature of lung and thorax and decrease in muscle strength. As mentioned above, PEFR significantly decreases with an increase in the level of FBS and PPBS.

\section{Limitations and scope}

It seems to be necessary to repeat PFTs and to assess the changes in pulmonary functions among the same subjects.

\section{Conclusions}

This study was undertaken to study the effect of diabetes mellitus on pulmonary functions. Pulmonary functions in diabetes mellitus and controls were statistically compared to resolve this. 
The following conclusion can be drawn from the results of the present study.

01. The pulmonary functions FVC, FEV1, FEF25\%-75\% and PEFR are decreased in diabetes mellitus compared to controls. FEV1/FVC\% slightly increased in diabetes mellitus, which is indicative of the restrictive pulmonary disorder.

02. Spirometric values were consistently lower in subjects with diabetes mellitus than in nondiabetics. The differences reached statistical significance only for the forced vital capacity, PEF and FEV / FVC.

03. Males with diabetes tended to be affected more than females, attaining lower levels of their percentage of predicted values.

04. There is a negative correlation between FBS levels and pulmonary functions FVC, FEV1, FEF25\%-75\% and PEFR which is highly significant. There is a linear relationship between increasing FBS and FEV1/FVC\% which is indicative of the restrictive pulmonary disorder.

05. There was a mean decline of FVC of $200 \mathrm{ml}$ among diabetic males. And a decline of $240 \mathrm{ml}$ among diabetic females as compared to diabetic controls. There was a decline of FEV1 of $180 \mathrm{ml}$ among men and $120 \mathrm{~L}$ among women.

Hence, we conclude that strict glycaemic control \& regular breathing exercises to strengthen the respiratory muscles may improve the pulmonary function test in patients.

\section{What does the study add to the existing knowledge?}

Over a long observation course, the relationship between the plasma glucose concentration and the PFTs can be elucidated.

\section{Contribution of authors}

Both authors contributed similarly to the study process, conduct and manuscript preparation.

\section{Reference}

01. Khaled AA, Sekaran M, Ikram SI. Type 2 Diabetes and Vascular Complications- A pathophysiologic view. Biomedical Research. 2010;21(2)147-55.

[Crossref]
02. American Diabetes Association. Diagnosis and classification of diabetes mellitus. Diabetes Care. 2009;32(Suppl 1)S62-S67.

doi: $10.2337 /$ dc09-S062 [Crossref]

03. King $H$, Aubert RE, Herman WH. Global burden of diabetes, 1995-2025- prevalence, numerical estimates, and projections. Diabetes Care. 1998 Sep;21(9)1414-31.

doi: $10.2337 /$ diacare.21.9.1414 [Crossref]

04. Benbassat CA, Stern E, Kramer M, Lebzelter J, Blum I, Fink G. Pulmonary function in patients with diabetes mellitus. Am J Med Sci. 2001 Sep;322(3)127-32.

doi: 10.1097/00000441-200109000-00003 [Crossref]

05. Kennedy WR, Navarro X, Sakuta M, Mandell $H$, Knox CK, Sutherland DE. Physiological and clinical correlates of cardiorespiratory reflexes in diabetes mellitus. Diabetes Care. 1989 Jun;12(6)399-408.

Doi 10.2337/diacare.12.6.399 [Crossref]

06. Vinik AI, Maser ER, Mitchell BD, Freeman R. Diabetic autonomic neuropathy. Diabetes Care. 2003 May;26(5)1553-1579.

doi: $10.2337 /$ diacare.26.5.1553 [Crossref]

07. Sandler M. Is the lung a 'target organ' in diabetes mellitus?. Arch Intern Med. 1990 Jul; 150(7)1385-8.

[Crossref]

08. Shah SH, Sonawane P, Nahar P, Vaidya S, Salvi S. Pulmonary function tests in type 2 diabetes mellitus and their association with glycemic control and duration of the disease. Lung India. 2013;30(2)108-112. doi:10.4103/0970-2113.11041 [Crossref]

09. Meo SA, Al-Drees AM, Shah SF, Arif M, AlRubean $K$. Lung function in type 1 Saudi diabetic patients. Saudi Med J. 2005 Nov;26(11)1728-33.

[Crossref]

10. Meo SA, Al-Drees AM, Arif M, Al-Rubean K. Lung function in type 2 Saudi diabetic patients. Saudi Med J. 2006 Mar;27(3)338-43.

[Crossref] 
11. Melo E, Vianna EO, Gallo L Jr, Foss MC, TerraFilho J. Pulmonary function, cholinergic bronchomotor tone, and cardiac autonomic abnormalities in type 2 diabetic patients. Braz J Med Biol Res. 2003 Mar;36(3)291-9.

doi: $10.1590 /$ s0100-879x2003000300002 [Crossref]

12. Hsia CC, Raskin P. Lung function changes related to diabetes mellitus. Diabetes Technol Ther. 2007 Jun(9)Suppl 1;S73-82.

doi: 10.1089/dia.2007.0227 [Crossref]
13. Lange $P$, Parner $J$, Schnohr $P$, Jensen $G$. Copenhagen City Heart Study- Iongitudinal analysis of ventilatory capacity in diabetic and nondiabetic adults. Eur Respir J. 2002 Dec;20(6)1406-12.

doi: 10.1183/09031936.02.00050502 [Crossref]

14. Alvin CP, Kasper DL, Fauci AS, Longo DL, Braunwald E, Hauser SL, Jameson LJ, editors. Harrison's principles of Internal Medicine. 16th edn, New York- McGraw Hill Companies. 2005(2)2152-2180.

[Crossref] 